\title{
Molecular structure investigation and tautomerism aspects of (E)-3-benzylideneindolin-2-one
}

\author{
ASSEM BARAKAT ${ }^{\mathrm{a}, \mathrm{c}, *}$, ABDULLAH MOHAMMED AL-MAJID $^{\mathrm{a}}$, \\ MOHAMMAD SHAHIDUL ISLAM ${ }^{\mathrm{a}}$, M ALI $^{\mathrm{a}}$, SAIED M SOLIMAN $^{\mathrm{b}, \mathrm{c}}$, \\ MOHAMMED RAFIQ HUSSAIN SIDDIQUI ${ }^{\mathrm{a}}$, HAZEM A GHABBOUR ${ }^{\mathrm{d}}$ and \\ HOONG-KUN FUN ${ }^{\text {d,e }}$

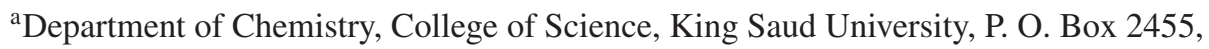 \\ Riyadh 11451, Saudi Arabia \\ ${ }^{b}$ Department of Chemistry, College of Science \& Arts, King Abdulaziz University, \\ P.O. Box 344, Rabigh 21911, Saudi Arabia \\ ${ }^{\mathrm{c}}$ Department of Chemistry, Faculty of Science, Alexandria University, P.O. Box 426, Ibrahimia, \\ Alexandria 21321, Egypt \\ ${ }^{\mathrm{d} D e p a r t m e n t ~ o f ~ P h a r m a c e u t i c a l ~ C h e m i s t r y, ~ C o l l e g e ~ o f ~ P h a r m a c y, ~ K i n g ~ S a u d ~ U n i v e r s i t y, ~}$ \\ P.O. Box 2457, Riyadh 11451, Saudi Arabia

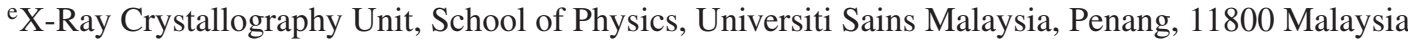 \\ e-mail: ambarakat@ksu.edu.sa
}

MS received 11 March 2015; revised 26 May 2015; accepted 27 May 2015

\begin{abstract}
The synthesis and spectral characterization of the (E)-3-benzylideneindolin-2-one is reported. The compound crystallized in the monoclinic system with space group $P 2{ }_{1} / n$ with cell coordinates $a=3.9849$ (2) $\AA, b=22.2236$ (9) $\AA, c=12.2501$ (5) $\AA, \beta=95.0535(12)^{\circ}, V=1080.64$ (8) $\AA^{3}$, and $Z=4$. In the crystal, molecules are packed in chains formed via weak intermolecular C13-H13A ... O1 and N1-H1N1...O1 hydrogen bonding. The relative stabilities of the two tautomeric isomers of $\mathbf{3}$ are calculated by DFT/B3LYP method using 6-311G(d,p) basis set in gas phase and in solution. The quantum chemical calculations, NMR studies and the XRD analyses showed that the keto form T0 is the only form that could exist in gas, solution and solid phases respectively. The calculated geometric parameters of the dimer molecule showed better agreement with the XRD data than those obtained for single isolated molecule. This shed light on the effect of intermolecular interactions on the calculated geometric parameters. MEP study showed that, the O-atom and the NH proton are the most reactive $\mathrm{H}$-acceptor and $\mathrm{H}$-donor sites, respectively. The $\mathrm{N}-\mathrm{H}$...O H-bonding interactions increased the negative charge at the $\mathrm{O}$-atoms and the positive charge of the $\mathrm{NH}$ protons compared to the monomer unit.
\end{abstract}

Keywords. Indolin-2-one; crystallography; DFT-computation; tautomerism

\section{Introduction}

Heterocyclic compounds containing 5- or 6-membered ring are important for their diverse biological activities. ${ }^{1}$ For example, indole scaffold, which represents a large family of heterocyclic compounds, have been extensively explored for development of pharmaceutically important molecules. The chemistry of 2-indoline, especially its derivatives has received considerable attention due to their synthetic and biological importance, such as antitumor agents, ${ }^{2}$ most of which appear to act as inhibitors of various protein kinase families, particularly receptor tyrosine kinases (RTKs) and serine/ threonine-specific protein kinases, such as the cyclindependent kinases (CDKs). ${ }^{3}$ Semaxanib (figure 1), the

\footnotetext{
*For correspondence
}

first synthetic indolin-2-one small-molecule compound showed a potent activity against vascular endothelial growth factor (VEGF) receptor-1 and -2 tyrosine kinases, ${ }^{4,5}$ but the development of Semaxanib was not pursued due to the severe toxicity and negative results in Phase II/III studies. ${ }^{6,7}$ For example, Sunitinib (figure 1), the first kinase inhibitor of the indolin-2-one type targeting at multiple kinases, was approved for the treatment of renal cell carcinoma and gastrointestinal stromal tumor. ${ }^{7-13}$ The 2-indoline moiety has been incorporated into a wide variety of therapeutically important compounds, for example Indirubin, an active ingredient of a traditional Chinese medicine recipe, has been applied to treat chronic myelocytic leukemia (figure 1). ${ }^{14}$ In addition, these compounds could exert antibacterial activities as was shown previously for several oxindole derivatives. ${ }^{15-17}$ The Aldol condensation reaction is a 


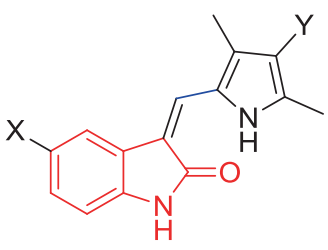

Semaxanib $(X=Y=H)$

Sunitinib $\left(X=F ; Y=\mathrm{Et}_{2} \mathrm{~N}\left(\mathrm{CH}_{2}\right)_{2} \mathrm{NHCO}\right)$

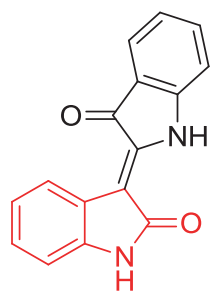

Indirubin
Figure 1. Biologically active 2-indoline derivatives.

useful transformation that has been widely employed for carbon-carbon bond formation in organic synthesis. ${ }^{18}$

Tautomerism is the ability of certain organic molecules to exist in isomeric structures. In biology, tautomers of nucleobases play a pivotal role in hydrogen bonding interactions and stabilize the structure of DNA. Considering the importance of tautomerism in the pharmaceutical industry, identification of the correct tautomer is recognized as one of the important tasks in pharmacophore-based virtual screening and drug discovery programs. ${ }^{19,20}$ In view of the above mentioned facts and in continuation of our interest, ${ }^{21-25}$ the structure of (E)-3-benzylideneindolin-2-one (3) was unambiguously elucidated by single-crystal X-ray diffraction technique and elemental analysis. The present work aims to study the molecular structure, electronic and spectroscopic properties of the newly synthesized
(E)-3-benzylideneindolin-2-one. The stability of the two suggested tautomers in the gas phase and in solution has been predicted using the total energies and thermodynamic parameters obtained from the DFT/B3LYP calculations. The effect of the intermolecular N-H$\mathrm{O} \mathrm{H}$-bonding interactions on the calculated geometric parameters has been tested. The electronic spectra were assigned with the aid of the TD-DFT calculations.

\section{Experimental}

\subsection{Synthesis and spectral investigations}

A mixture of indolin-2-one 1 (1.5 mmol, $200 \mathrm{mg})$, benzaldehyde $2(1.5 \mathrm{mmol}, 159 \mathrm{mg})$ and $\mathrm{NHEt}_{2}(1.5 \mathrm{mmol}$, $155 \mu \mathrm{L}$ ) in $3 \mathrm{~mL}$ water was stirred at room temperature for 3-5 h until TLC showed complete disappearance of the reactants. The product was precipitated and filtered off washed with $20 \mathrm{~mL}$ water, dried and recrystallized from $\mathrm{DCM} / \mathrm{EtOH} / \mathrm{Et}_{2} \mathrm{O}$ to afford the pure product 3. M.p. $138^{\circ} \mathrm{C}$; IR $(\mathrm{KBr}) v_{\max } / \mathrm{cm}^{-1}: 3151,3079$, 3024, 2898, 2833, 1707, 1613, 1490, 1360; ${ }^{1} \mathrm{H}-\mathrm{NMR}$ (400 MHz; DMSO): 6.82 (H, t, $J=7.2, \mathrm{Ph}$ ), 7.20 (H, $\mathrm{t}, J=7.2, \mathrm{Ph}), 7.52-7.48(4 \mathrm{H}, \mathrm{m}, \mathrm{Ph}), 7.62(1 \mathrm{H}, \mathrm{s}$, $\mathrm{C}=\mathrm{CH}), 7.69(3 \mathrm{H}, \mathrm{m}, \mathrm{Ph}), 10.61(1 \mathrm{H}$, brs, $\mathrm{NH}) ;{ }^{13} \mathrm{C}-$ NMR (100 MHz; DMSO) 168.6, 142.9, 135., 134.4, 130.2, 129.7, 129.3, 128.7, 127.7, 122.3, 121.1, 120.9, 110.1;MS m/z(\%):221.25 [M+, 90\%]; Anal. calcd. for

Table 1. The crystal and experimental data of $\mathbf{3}$.

$$
\begin{aligned}
& \mathrm{C}_{30} \mathrm{H}_{22} \mathrm{~N}_{2} \mathrm{O}_{2} \\
& \mathrm{Mr}=442.49 \\
& \text { Monoclinic, } \mathrm{P} 21 / \mathrm{n} \\
& \mathrm{a}=3.9849(2) \AA \\
& \mathrm{b}=22.2236(9) \AA \\
& \mathrm{c}=12.2501(5) \AA \\
& \beta=95.0535(12)^{\circ} \\
& \mathrm{V}=1080.64(8) \AA 3 \\
& \mathrm{Z}=2
\end{aligned}
$$

Data collection

Bruker D8 Venture diffractometer

55332 measured reflections

3313 independent reflections

3163 reflections with $\mathrm{I}>2 \sigma(\mathrm{I})$

Tmin $=0.93$, Tmax $=0.96$

Rint $=0.023$

\section{Refinement}

Refinement on F2

Least-squares matrix: full

$\mathrm{R}[\mathrm{F} 2>2 \sigma(\mathrm{F} 2)]=0.043$

$\mathrm{wR}(\mathrm{F} 2)=0.118$

$\mathrm{S}=0.99$

3313 reflections 158 parameters

$$
\begin{aligned}
& \mathrm{Dx}=1.360 \mathrm{Mg} \mathrm{m}-3 \\
& \text { Mo K } \alpha \text { radiation, } \lambda=0.71073 \AA \\
& \text { Cell parameters from } 9882 \text { reflections } \\
& \theta=2.5-30.5^{\circ} \\
& \mu=0.09 \mathrm{~mm}-1 \\
& \mathrm{~T}=100 \mathrm{~K} \\
& \mathrm{Block}, \text { clear intense yellow } \\
& 0.69 \times 0.55 \times 0.45 \mathrm{~mm} \\
& \mathrm{~F}(000)=464
\end{aligned}
$$

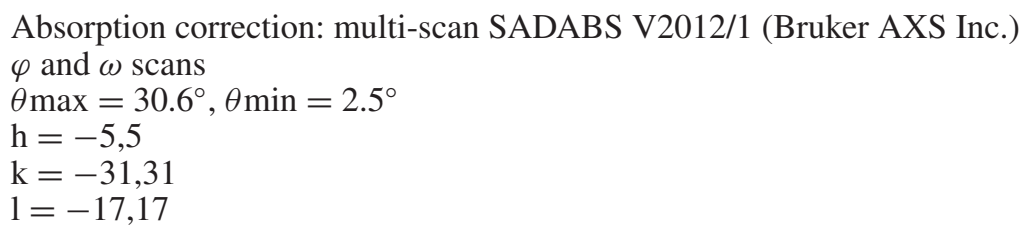

Hydrogen site location: mixed

$\mathrm{H}$ atoms treated by a mixture of independent and constrained refinement $\mathrm{w}=1 /[\sigma 2(\mathrm{Fo} 2)+(0.076 \mathrm{P}) 2+0.376 \mathrm{P}]$ where $\mathrm{P}=(\mathrm{Fo} 2+2 \mathrm{Fc} 2) / 3$ $(\Delta / \sigma) \max =0.001$

$\Delta \rho \max =0.40$ e $\AA-3$

$\Delta \rho \min =-0.33$ e $\AA-3$

Extinction correction: none 
$\mathrm{C}_{15} \mathrm{H}_{11} \mathrm{NO}$ : C, 81.43; H, 5.01; N, 6.33\%; Found: C, $81.45 ; \mathrm{H}, 5.00 ; \mathrm{N}, 6.34 \%$.

The relevant spectral grade solvents were used throughout the spectroscopic investigations. UV spectra were recorded on a Perkin Elmer, Lambda 35, UV/Vis spectrophotometer; 3 (methanol): 203, 240 252, 319 and $380 \mathrm{~nm}$. IR spectra were recorded on a Nicolet 6700 FT-IR spectrophotometer and NMR spectra on a Varian Mercury Jeol-400 NMR spectrometer operating at a proton frequency of $400 \mathrm{MHz}$ (carbon frequency $=100$ $\mathrm{MHz}$ ). Mass spectra were recorded on a Jeol of JMS$600 \mathrm{H}$. Elemental analysis were performed on Elmer 2400 Elemental Analyzer; CHN mode.

\subsection{Single crystal X-ray measurements}

Slow evaporation of DCM/EtOH/Et ${ }_{2} \mathrm{O}$ solution of pure compound 3 yielded yellow crystals. A crystal of dimensions, $0.69 \times 0.55 \times 0.45 \mathrm{~mm}$ was selected for X-ray diffraction analysis. Data were collected on a Bruker APEX-II D8 Venture area diffractometer, equipped with graphite monochromatic Mo $\mathrm{K} \alpha$ radiation at 100 $\mathrm{K}$. Cell refinement and data reduction were carried out by Bruker SAINT SHELXS-9726,27 was used to solve structure. The final refinement was carried out by fullmatrix least-squares techniques with anisotropic thermal data for nonhydrogen atoms on $F^{2}$ (table 1). All the hydrogen atoms were placed in calculated positions. The molecular structure of $\mathbf{3}$ is illustrated in figure 2 . The geometric parameters of the crystal structure of $\mathbf{3}$ are provided in Supporting Information.

\subsection{Computations}

All calculations for the studied tautomers were carried out using Gaussian 03 software. ${ }^{28}$ The calculations were

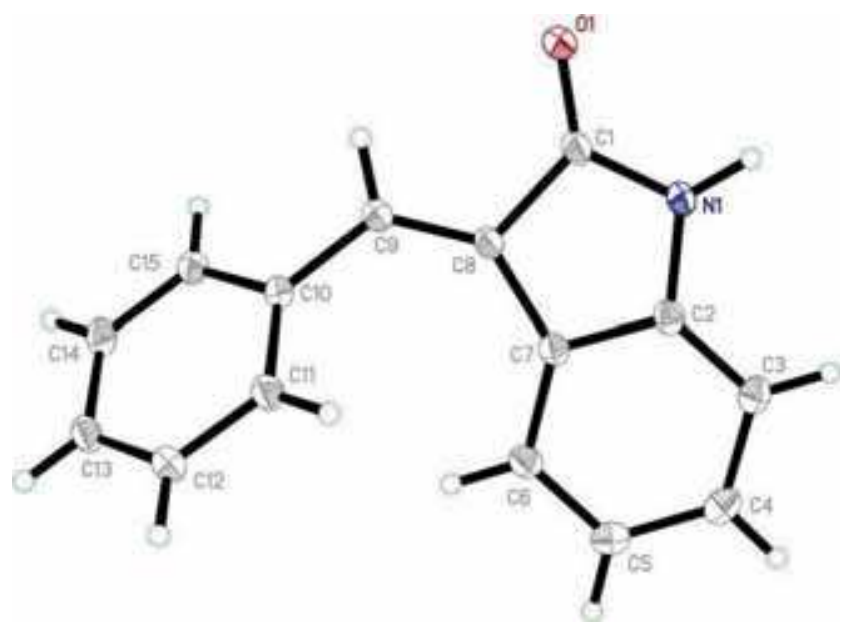

Figure 2. The ORTEP diagram of the final X-ray model of $\mathbf{3}$ with displacement ellipsoids drawn at 30\% probability level. performed by DFT/B3LYP method using 6-311G(d,p) basis set. The input file was taken from the CIF obtained from the X-ray single crystal measurement. The geometries were optimized by minimizing the energies with respect to all the geometrical parameters without imposing any molecular symmetry constraints. Gauss View 4.1 has been used to visualize the structures of the optimized geometries. ${ }^{29}$ The computational study was first carried out in gas phase. Then, the SelfConsistent Reaction Field (SCRF) theory ${ }^{30}$ with Polarized Continuum Model (PCM) was used to predict the effect of solvent on the stability of the tautomers. ${ }^{31}$ Optimized structural parameters were used in the electronic property and isotropic chemical shift calculations. Local minima were verified by the absence of any imaginary frequency modes. Zero-point and thermal corrections to energy and Gibbs free energy were calculated at the same level of theory to produce the corrected energy values. The electronic spectra of the compound were calculated by the TD-DFT method in different solvents to predict the effect of solvent on the electronic spectra compared to the gas phase and for visualizing HOMO and LUMO states. The natural atomic charges were calculated using NBO calculations as implemented in the Gaussian 03 package $^{32}$ at the DFT/B3LYP level. The nuclear magnetic resonance (NMR) chemical shift calculations were performed using GIAO method $^{33,34}$ at the same level of theory.

\section{Results and Discussion}

\subsection{Synthesis and characterization}

The key (E)-3-benzylideneindolin-2-one $\mathbf{3}$ was synthesized by a base-catalyzed Aldol condensation reaction between equimolar amounts of indolin-2-one and benzaldehyde in excellent yield (89\%) as illustrated in scheme 1 . The chemical structure of $\mathbf{3}$ was elucidated by analysis of its spectroscopic data including GCMS, ${ }^{1} \mathrm{H},{ }^{13} \mathrm{C}$ NMR, COSY, HETCOR, IR and X-ray single crystal structure.

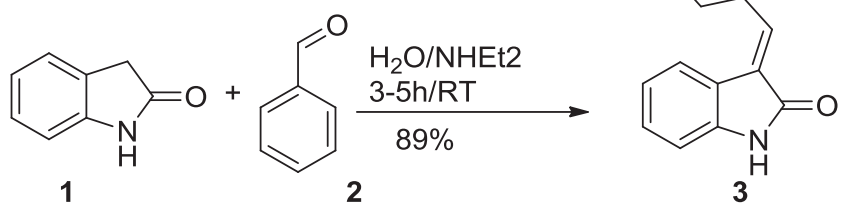

Scheme 1. Preparation of the title compound 3. 


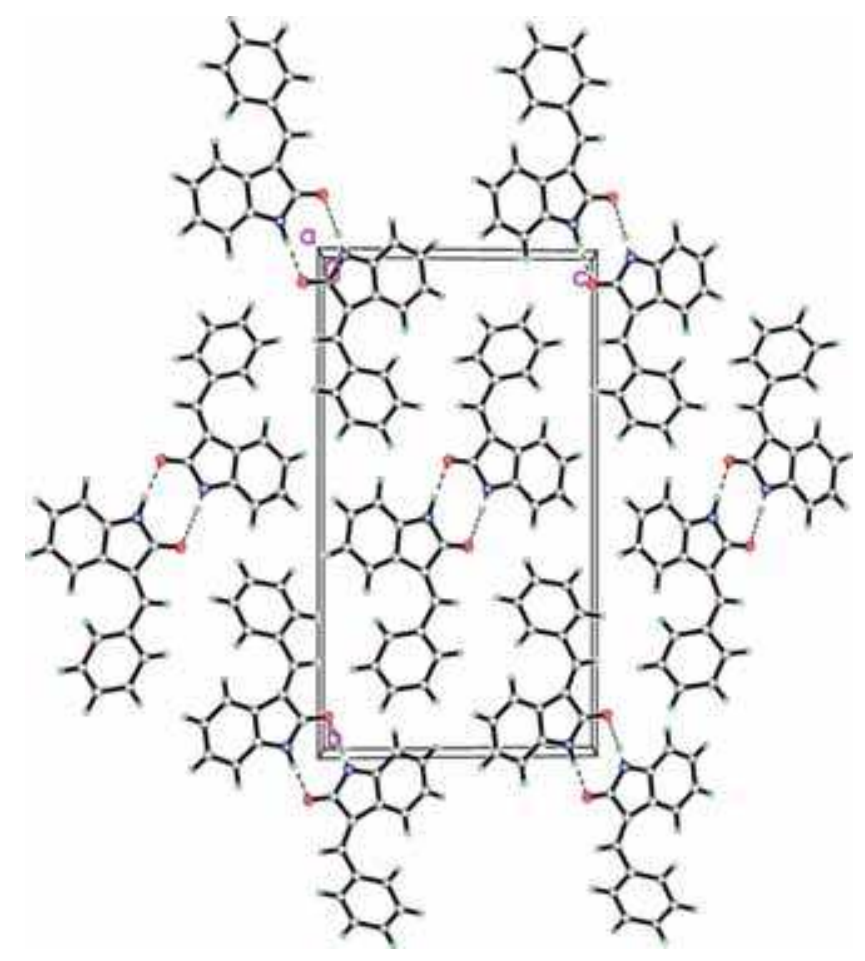

Figure 3. The crystal packing of 3. Dashed line indicates the intermolecular interactions.

\subsection{Crystal Structure of 3}

The molecular structure of $\mathbf{3}$ consists of two rings; phenyl (C10-C15) and indolin-2-one rings (C1/N1/C2C8) linked together through C9 (figure 2). The dihedral angle between the indolin-2-one and the phenyl ring is $49.26(2)^{\circ}$. The bond length between C8-C9 is 1.3480 (11) A which indicated that it is double bond (table S1, Supplementary Information). Molecules form dimers connected by $\mathrm{N}-\mathrm{H} \cdots \mathrm{O}$ and $\mathrm{C}-\mathrm{H} \cdots \mathrm{O}$ interactions to form chains along the $b$-axis (figure 3 and table 2).

\subsection{DFT calculations}

3.3a Stabilities, Relative energies and Thermodynamic parameters of 3: $\mathbf{3}$ has one carbonyl and one $\mathrm{NH}$ group and so it can exhibit the tautomeric ketoenol structures, T0 and T1 as shown in scheme 2. The total energies and thermodynamic parameters of these isomers are calculated using B3LYP/6-311G(d,p) calculations. The calculated energies of these tautomers

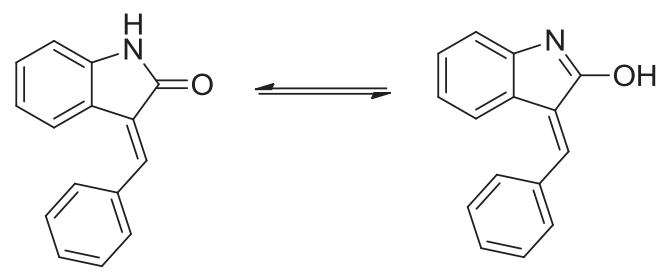

Scheme 2. The tautomeric equilibrium reaction of 3. T0 (keto, left) and $\mathrm{T} 1$ (enol, right).

are compared in table S2 (Supplementary Information) which shows that T0 is lower in energy by 14.67 $\mathrm{kcal} / \mathrm{mol}$ be than T1. The relative abundance of the two tautomers was calculated using the equilibrium constant (K) calculated from the relation: $\Delta \mathrm{G}=-\mathrm{RT} \ln \mathrm{K}$, where $\Delta \mathrm{G}$ denotes the difference between the Gibbs free energies relative to the most stable one. The abundance of the most stable species, T0 is equal to $100 \%$ at $298 \mathrm{~K}$ in the gas phase as well as in solutions of different polarities. T1 has zero population and is expected to be of no importance. We noted that the energy barrier between the two tautomers is the least in DMSO. Experimentally, the NMR spectrum in different solvents (figures in Supplementary Information) revealed that $\mathbf{3}$ exists only in the keto form $\mathrm{T} 0$ in solution. We noted only the proton signal of the NH in DMSO but not in other solvents. Anyway, T0 is the only species that could exist in solution. Furthermore, GIAO-calculated chemical shifts of both tautomers in DMSO were compared with the experimental data in the same medium and the results are given in table S3 (Supplementary Information). The calculated RMSD showed better agreement between experimental and calculated chemical shifts for $\mathrm{T} 0$ than $\mathrm{T} 1$ form.

3.3b Molecular Geometry: The optimized bond lengths and bond angles obtained for the stable tautomer (T0) are given in table S4 (Supplementary Information). The atom numbering of the optimized structure is shown in figure 4. The point group of the stable isomer (T0) is $C_{1}$. The optimized geometrical parameters (bond distances and bond angles) and the experimental data obtained from the CIF are compared in figure 5. In general, the geometric parameters are predicted very well. The maximum deviations of the bond distance and bond angle values are $0.024 \AA$ (N2-C3) and 3.1 $1^{\circ}$ (C14-C15-C17) respectively. The reason for these deviations can be

Table 2. Hydrogen-bond geometry $\left(\AA,^{\circ}\right)$.

\begin{tabular}{lllll}
\hline $\mathrm{D}-\mathrm{H} \cdots \mathrm{A}$ & $\mathrm{D}-\mathrm{H}$ & $\mathrm{H} \cdots \mathrm{A}$ & $\mathrm{D} \cdots \mathrm{A}$ & $\mathrm{D}-\mathrm{H} \cdots \mathrm{A}$ \\
$\mathrm{C} 13-\mathrm{H} 13 \mathrm{~A} \cdots \mathrm{O} 1 \mathrm{ii}$ & 0.93 & 2.58 & $3.2517(11)$ & 129.0 \\
\hline
\end{tabular}

Symmetry codes: (i) $-\mathrm{x}+2,-\mathrm{y},-\mathrm{z}+2$; (ii) $\mathrm{x}-1 / 2,-\mathrm{y}+1 / 2, \mathrm{z}+1 / 2$. 

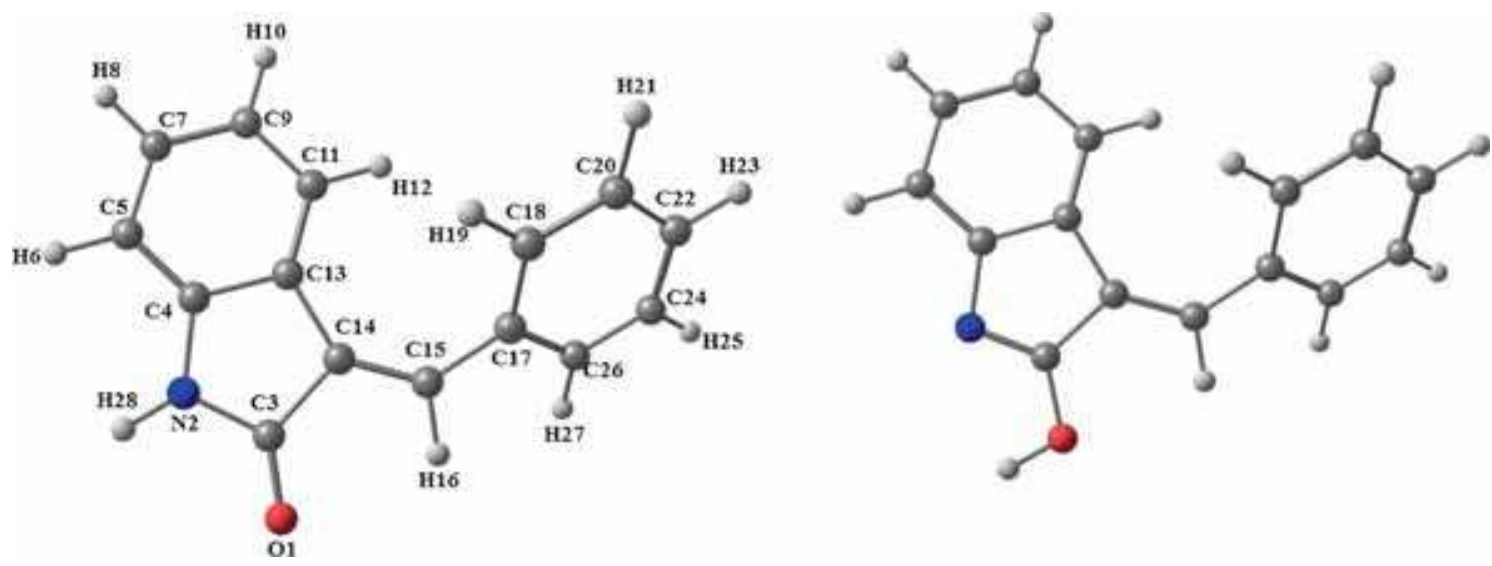

Figure 4. The calculated optimized structures of the suggested tautomers of the studied compound.

attributed to the different phases between calculations and experiments. The latter is for the solid phase where the intermolecular interactions affect the geometric parameters while the calculation is for single isolated molecule in the gas phase. In order to assess the effect of the intermolecular N-H. .O H-bonding interactions on the geometric parameters, a dimer unit of $\mathbf{3}$ has been calculated using the same level of theory (figure 6). The
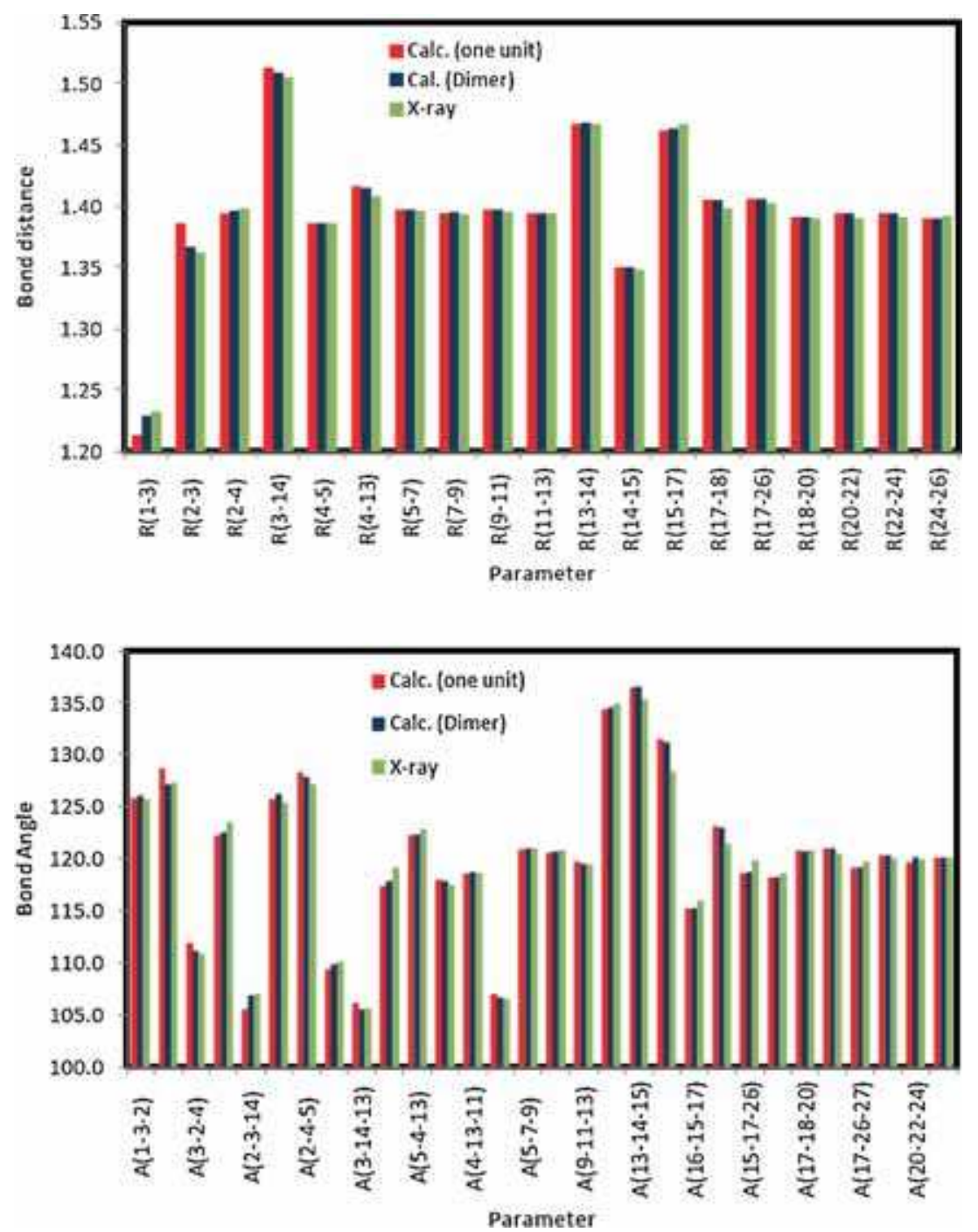

Figure 5. Comparison between the calculated and experimental geometric parameters of the studied systems. 


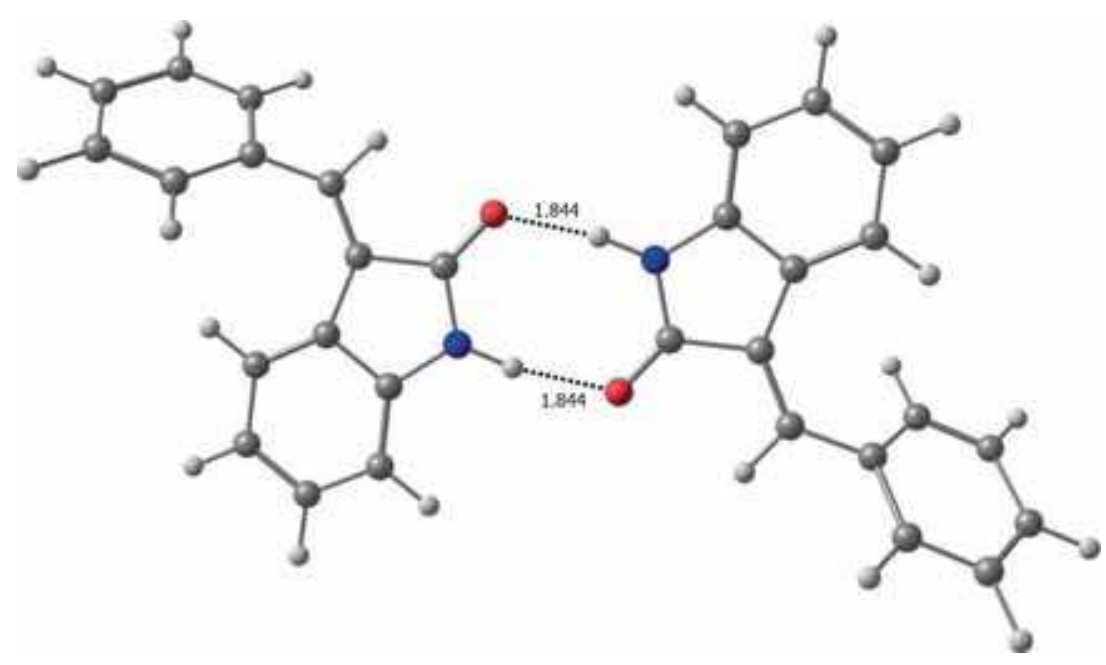

Figure 6. The calculated optimized structures of the dimer unit of the studied compound.

results of geometric parameters are given in table S4 (Supplementary Information) and figure 5. The dimer possesses $\mathrm{C}_{\mathrm{i}}$ point group where the two $\mathrm{N}-\mathrm{H}$...O H-bonds are equivalent $(1.844 \AA)$. The calculated root mean square deviations for the calculated bond distances and bond angles of the single and dimer molecules are given in table S4 (Supplementary Information). It is obvious that the geometric parameters of the dimer are in in better agreement with the $\mathrm{X}$ ray data than the isolated single molecule. On other hand, the solvent effect on the computed bond distances is almost insignificant in nonpolar solvent such as cyclohexane. In contrast, there is a noticeable change of the $\mathrm{C}-\mathrm{N}$ and $\mathrm{C}=\mathrm{O}$ bond distances in polar solvents. These bonds are of high polarity and can be involved in the solute-solvent interactions with polar solvents in solution. In general, the $\mathrm{C}-\mathrm{N}$ bonds are shortened while the $\mathrm{C}=\mathrm{O}$ bond distances are increased due to solvent effect in solution.

Distribution of positive and negative charges has vital role in the application of quantum chemical calculations to molecular system because of atomic charges affect dipole moment, molecular polarizability, electronic structure, acidity-basicity behavior and many other properties of the molecular system. ${ }^{35}$ These electronic properties have strong relations to the biological activity of compound. The natural atomic charges (NAC) of the tautomer (T0) calculated using the DFT/B3LYP method are collected in table S5 (Supplementary Information). From the NAC values listed in this table, the $\mathrm{NH}$ proton is the most electropositive atom while the $\mathrm{O}$ and $\mathrm{N}$-atoms are the most electronegative sites. The dipole moment of the tautomer T0 is calculated to be $2.8935 \mathrm{D}$ in the gas phase. In solution the dipole

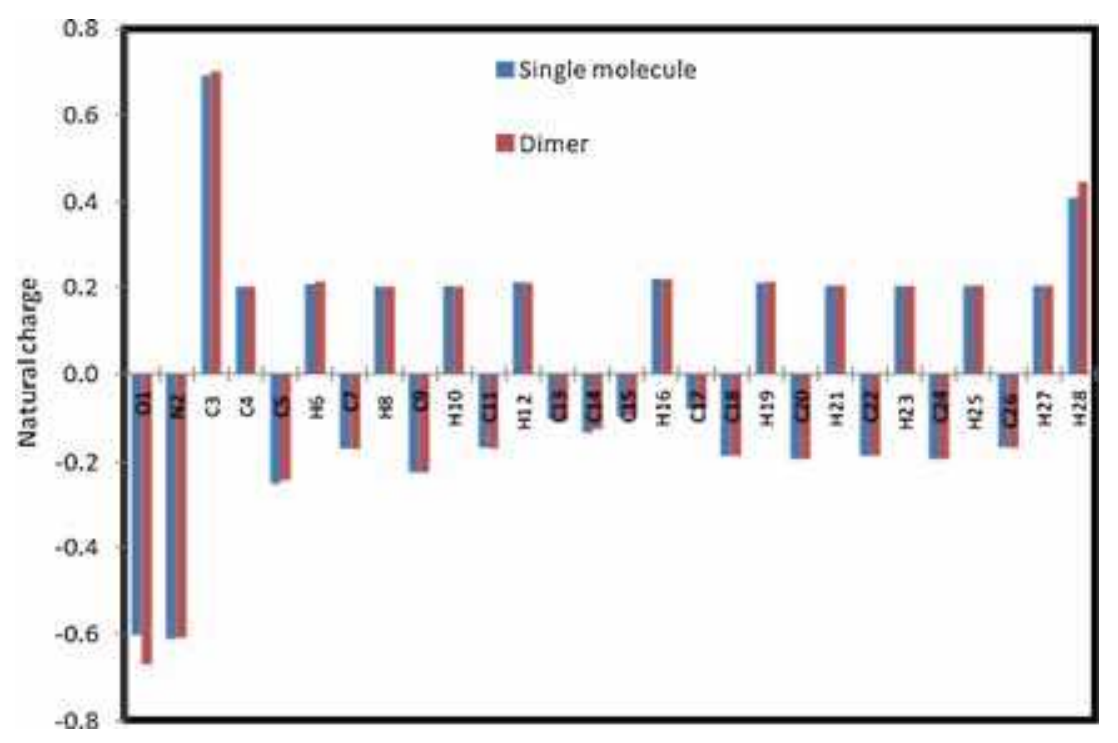

Figure 7. The calculated natural charges of the single and dimer molecules. 


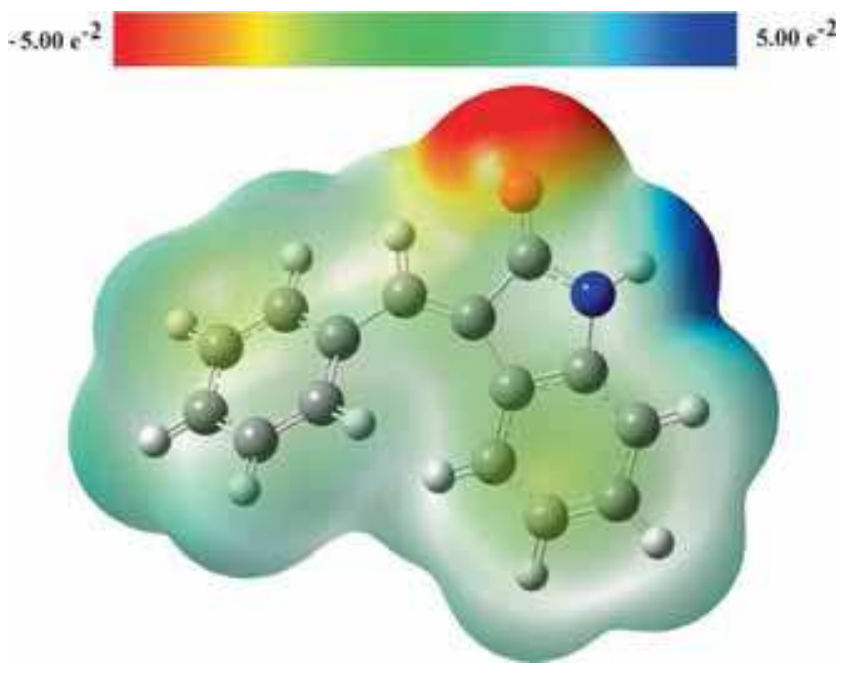

Figure 8. Molecular electrostatic potentials (MEP) mapped on the electron density surface calculated by the DFT/B3LYP method for the stable tautomer (T0).

moments are higher in the more polar solvents than the nonpolar one (cyclohexane). The formation of intermolecular $\mathrm{N}-\mathrm{H}-\mathrm{O} \mathrm{H}$-bonds affect significantly the natural charge values of the $\mathrm{O}$ - and $\mathrm{H}$-sites included in these interactions (figure 7). It could be seen that the $\mathrm{O}$ atoms are shifted to charge density that is more negative while the $\mathrm{H}$-atoms are shifted to higher positive charge densities. The calculated dipole moment of this dimer molecule is zero.

\section{3c Molecular electrostatic Potential (MEP):} Electrostatic potential maps are very useful for three-dimensional diagrams used to visualize the charge distributions and charge related properties of molecules. In addition, MEP picture has been used in studies of biological recognition and hydrogen bonding interactions. ${ }^{36,37}$ The MEP of the stable tautomer calculated using B3LYP with $6-311 \mathrm{G}(\mathrm{d}, \mathrm{p})$ basis set is used to predict the reactive sites for making intermolecular $\mathrm{H}$ bonding interactions. The negative (red) regions of the

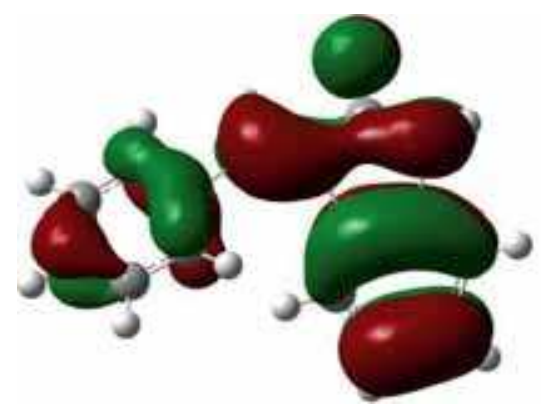

$\mathbf{E}_{\text {Hомо }}=-5.9191 \mathbf{e V}$
MEP are related to electrophilic reactivity (H-acceptor) and the positive (blue) regions to nucleophilic reactivity (H-donor), as shown in figure 8 . As can be seen from this figure, negative regions are mainly localized over the carbonyl oxygen atom ( -0.0559 a.u) while the maximum positive regions are localized on the hydrogen atom (0.0494 a.u) of the $\mathrm{NH}$ group. Hence, it would be predicted that the carbonyl oxygen atom and the amine hydrogen of the amide group are the most reactive sites for making intermolecular H-bonding interactions with the neighboring molecules in the crystal which agree with our reported X-ray structure.

\section{3d Frontier molecular orbitals (FMOs) and Elec-} tronic absorption spectra: The frontier molecular orbitals (HOMO and LUMO) are important quantum chemical parameters used to describe the molecular reactivity and the ability of a molecule for electron transport. The orbital energy level analysis of $\mathbf{3}$ showed that $\mathrm{E}_{\mathrm{HOMO}}$ and $\mathrm{E}_{\mathrm{Lumo}}$ values are $-5.9191 \mathrm{eV}$ and $-2.2316 \mathrm{eV}$ respectively. The HOMO-LUMO energy gap represents the lowest energy electronic transition. The HOMO-LUMO energy gap of $\mathbf{3}$ at the DFT level is $3.6874 \mathrm{eV}$. The HOMO and LUMO plots drawn by DFT-B3LYP method are shown in figure 9 . The HOMO and LUMO levels are totally delocalized because of the unsaturated nature of the system. Hence, the HOMO $\rightarrow$ LUMO electronic transition belongs to $\pi \rightarrow \pi *$ transition.

The possible electronic transitions in the UV-Visible spectrum of $\mathbf{3}$ was studied by the time-dependent density functional theory (TD-DFT). The first twenty spin allowed singlet-singlet excitations were calculated using TD-DFT calculations in the gas phase as well as in solution of different polarity solvents. The calculated electronic transitions with high oscillatory strengths are given in table 3. Theoretical UV-Visible spectra of 3 are shown in figure 10. The four most intense spectral bands are calculated at 204.4, 245.4, 320.8 and

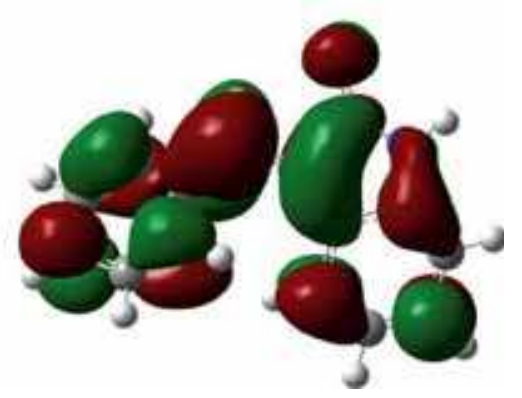

$\mathbf{E}_{\text {LUMO }}=-2.2316 \mathbf{e V}$

Figure 9. The ground state isodensity surface plots of the frontier molecular orbitals of the studied molecule. 
Table 3. The calculated electronic transitions of $\mathbf{3}$ using the TD-DFT method. $\lambda_{\max }$ in $\mathrm{nm}$.

\begin{tabular}{lccl}
\hline Solvent & $\lambda_{\max }$ & $\mathrm{f}_{\mathrm{osc}}$ & Major contribution \\
\hline Gas & 390.2 & 0.1305 & $\mathrm{H}-1 \rightarrow \mathrm{L}(10 \%), \mathrm{H} \rightarrow \mathrm{L}(79 \%)$ \\
& 320.8 & 0.3458 & $\mathrm{H}-1 \rightarrow \mathrm{L}(79 \%), \mathrm{H}-\mathrm{L} \rightarrow \mathrm{L}(13 \%), \mathrm{H}-1 \rightarrow \mathrm{L}+3(16 \%), \mathrm{H} \rightarrow \mathrm{L}+2(43 \%)$, \\
& 245.4 & 0.1228 & $\mathrm{H} \rightarrow \mathrm{L}+3(14 \%)$ \\
methanol & 204.4 & 0.1364 & $\mathrm{H}-6 \rightarrow \mathrm{L}(64 \%)$ \\
& 396.4 & 0.1528 & $\mathrm{H} \rightarrow \mathrm{L}(82 \%)$ \\
& 331.7 & 0.4182 & $\mathrm{H}-1 \rightarrow \mathrm{L}(82 \%)$ \\
DMSO & 246.2 & 0.1921 & $\mathrm{H}-1 \rightarrow \mathrm{L}+3(13 \%), \mathrm{H} \rightarrow \mathrm{L}+2(59 \%)$ \\
& 207.1 & 0.1612 & $\mathrm{H}-6 \rightarrow \mathrm{L}(66 \%)$ \\
& 395.8 & 0.1749 & $\mathrm{H} \rightarrow \mathrm{L}(92 \%)$ \\
Acetonitrile & 331.7 & 0.4215 & $\mathrm{H}-1 \rightarrow \mathrm{L}(92 \%)$ \\
& 246.3 & 0.1973 & $\mathrm{H}-1 \rightarrow \mathrm{L}+3(11 \%), \mathrm{H} \rightarrow \mathrm{L}+2(63 \%)$ \\
& 206.5 & 0.1611 & $\mathrm{H}-6 \rightarrow \mathrm{L}(72 \%)$ \\
Cyclohexane & 396.7 & 0.1549 & $\mathrm{H} \rightarrow \mathrm{L}(82 \%)$ \\
& 332.0 & 0.4194 & $\mathrm{H}-1 \rightarrow \mathrm{L}(82 \%)$ \\
& 246.3 & 0.1948 & $\mathrm{H}-1 \rightarrow \mathrm{L}+3(13 \%), \mathrm{H} \rightarrow \mathrm{L}+2(60 \%)$ \\
& 207.2 & 0.1620 & $\mathrm{H}-6 \rightarrow \mathrm{L}(66 \%)$ \\
& 395.5 & 0.1847 & $\mathrm{H} \rightarrow \mathrm{L}(83 \%)$ \\
& 329.3 & 0.4071 & $\mathrm{H}-1 \rightarrow \mathrm{L}(84 \%)$ \\
& 247.1 & 0.2018 & $\mathrm{H}-4 \rightarrow \mathrm{L}(12 \%), \mathrm{H}-1 \rightarrow \mathrm{L}+3(13 \%), \mathrm{H} \rightarrow \mathrm{L}+2(53 \%)$ \\
& 203.3 & 0.1177 & $\mathrm{H}-5 \rightarrow \mathrm{L}(12 \%), \mathrm{H}-4 \rightarrow \mathrm{L}+2(16 \%), \mathrm{H} \rightarrow \mathrm{L}+4(43 \%)$ \\
\hline
\end{tabular}

$390.2 \mathrm{~nm}$ in the gas phase. The experimental electronic spectrum in methanol showed good agreement with the calculated data in the same solvent. The two shortest wavelength bands are almost not affected by solvent effects. On other hand, the two longest wavelength transition bands are shifted to higher wavelength in presence of solvent. The observed red-shift in these absorption peaks may be ascribed to the decreased energies of $\pi *$-orbitals in solvents, which leads to lower energies of the $\pi-\pi *$ transition. It is noted that, the absorption intensities of all the spectral bands are higher in presence of solvent compared to the gas phase.

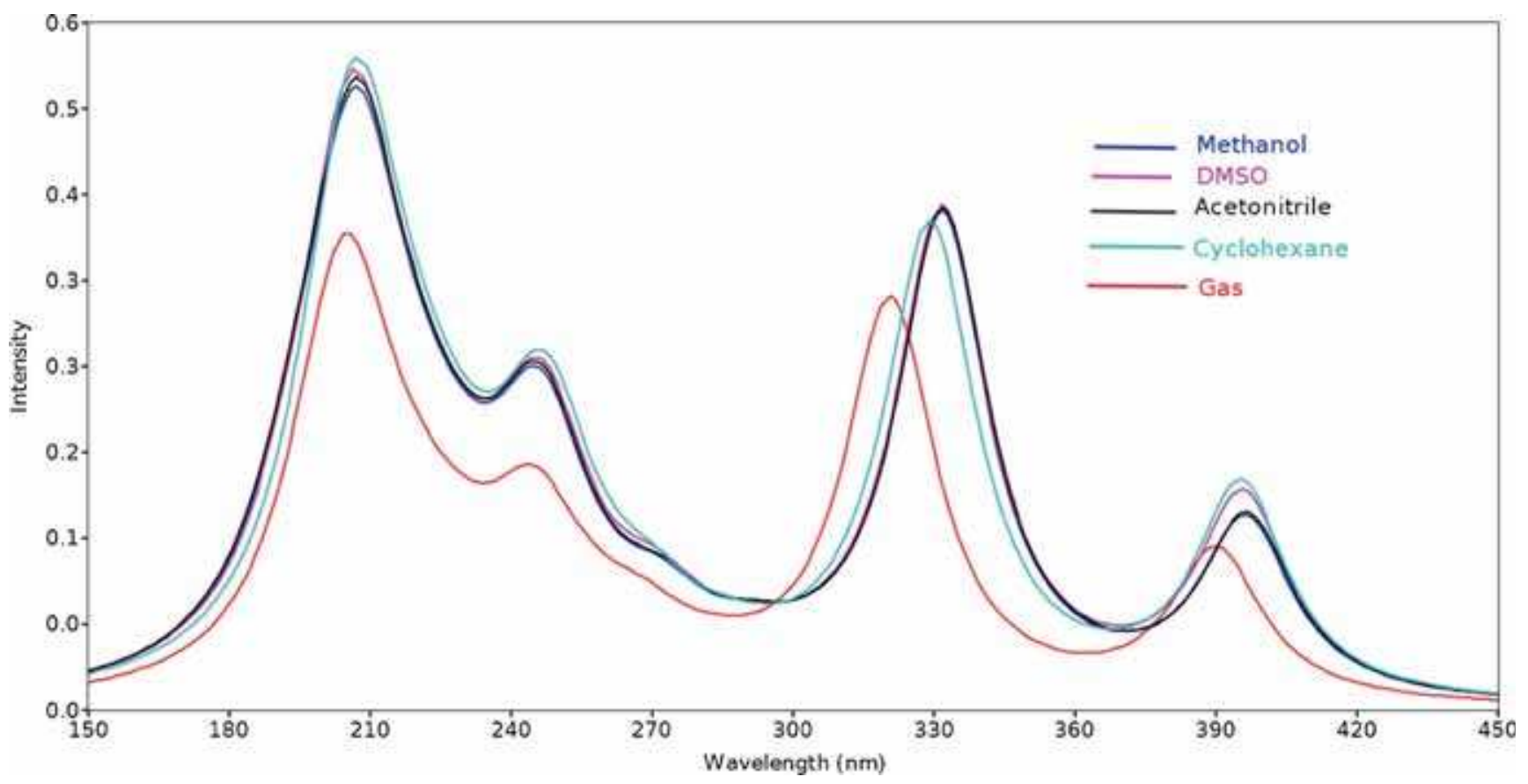

Figure 10. The calculated electronic spectra of the studied compound in gas phase and in solution using TD-DFT method. 


\section{Conclusions}

The (E)-3-benzylideneindolin-2-one $\mathbf{3}$ was synthesized and characterized using elemental analyses, FTIR, ${ }^{1} \mathrm{H}$, ${ }^{13} \mathrm{C}$-NMR spectra and X-ray single crystal structure. The stability and populations of the two suggested tautomers of $\mathbf{3}$ was predicted using the DFT/B3LYP method in gas phase and in solution. It is evident both theoretically and experimentally that $\mathbf{3}$ exists only in the keto form. The calculated geometric parameters of the dimer molecule showed better agreement with the $\mathrm{X}$-ray data than those for the single isolated molecule. It is found that consideration of $\mathrm{N}-\mathrm{H}$... O H-bonding interactions improve the calculated geometry. MEP study showed that the $\mathrm{O}$-atoms and the $\mathrm{NH}$ protons are the most reactive $\mathrm{H}$-acceptor and $\mathrm{H}$-donor sites, respectively, that are capable of intermolecular H-bond formation. The natural charges are calculated. It is found that, the $\mathrm{N}-\mathrm{H}$...O H-bond shifts the NAC values of the $\mathrm{O}$-atom to more negative values while the $\mathrm{H}$-atom is shifted to more positive values. The electronic spectra of $\mathbf{3}$ have been assigned on the basis of the TD-DFT calculations.

\section{Supplementary Information}

Additional information pertaining to characterization of the title compound $\mathbf{3}$ using NMR technique (figures S1S6), IR spectra (figures S7) X-ray, Geometric parameters (table S1) and DFT data (tables S2-S5) are given in supporting information. Supplementary Information is available at www.ias.ac.in/chemsci.

\section{Acknowledgements}

The authors would like to extend their sincere appreciation to the Deanship of Scientific Research at King Saud University for funding this Research group through NO(RG-044-1435-1436).

\section{References}

1. Chevan P, Mane A S and Shingare M S 2001 Indian J. Chem. 408339

2. Prakash C R and Raja S 2012 Mini-Rev. Med. Chem. 1298

3. Vine $\mathrm{K}$ L, Matesic L, Locke $\mathrm{J}$ M, Ranson $\mathrm{M}$ and Skropeta D 2009 Anti-Cancer Agents Med. Chem. 9 397

4. Fong $\mathrm{T}$ A, Shawver L K, Sun L, Tang C, App H, Powell T J, Kim Y H, Schreck R, Wang X, Risau W, Ullrich A, Hirth K P and McMahon G 1999 Cancer Res. 5999
5. Shaheen R M, Davis D W, Liu W, Zebrowski B K, Wilson M R, Bucana C D, McConkey D J, McMahon G and Ellis L M 1999 Cancer Res. 595412

6. Longo R, Sarmiento R, Fanelli M, Capaccetti B, Gattuso $\mathrm{D}$ and Gasparini G 2002 Angiogenesis 5237

7. Sun L, Liang C, Shirazian S, Zhou Y, Miller T, Cui J, Fukuda J Y, Chu J Y, Nematalla A, Wang X, Chen H, Sistla A, Luu T C, Tang F, Wei J and Tang C J 2003 Med. Chem. 461116

8. Farrell A M, Abrams T J, Yuen H A, Ngai T J, Louie S G, Yee K W, Wong L M, Hong W, Lee L B, Town A, Smolich B D, Manning W C, Murray L J, Heinrich M C and Cherrington J M 2003 Blood 1013597

9. Young E, Miele L, Tucker K B, Huang M, Wells J and Gu J W 2010 Cancer Biol. Ther. 10703

10. Ikezoe T, Nishioka C, Tasaka T, Yang Y, Komatsu N, Togitani K, Koeffler H P and Taguchi H 2006 Mol. Cancer Ther. 52522

11. Lyros O, Mueller A, Heidel F, Schimanski C C, Gockel I, Galle P R, Lang H and Moehler M 2010 Int. J. Cancer 1271197

12. Hui E P, Lui V W, Wong C S, Ma B B, Lau C P, Cheung C S, Ho K, Cheng S H, Ng M H and Chan A T 2011 Invest. New Drugs 291123

13. Chow L Q and Eckhardt S G 2000 J. Clin. Oncol. 25884

14. Xiao Z, Hao Y and Liu B 2002 Leuk. Lymphoma $\mathbf{4 3}$ 1763

15. Sridhar S K, Saravanan M and Ramesh A 2001 Eur. J. Med. Chem. 36615

16. Saudi M N S, El Semary M M A and El Sawaf G 2002 Pharmazie $\mathbf{5 7} 519$

17. Amal Raj A, Raghunathan R, Sridevikumari M R and Raman N 2003 Bioorg. Med. Chem. 11407

18. Heydri R and Tahamipour B 2011 Chin. Chem. Lett. 22 1281

19. Nanubolu J B, Sridhar B and Ravikumar K 2014 CrystEngComm 1610602

20. Ghosh S, Bag P P and Reddy C M 2011 Cryst. Growth Des. 113489

21. Barakat A, Al-Majid A M, Islam M S and Al-Othman Z A 2013 Tetrahedron 695185

22. Islam M S, Al-Majid A M, Al-Othman Z A and Barakat A 2014 Tetrahedron: Asymmetry 25245

23. Barakat A, Al-Majid A M, Al-Najjar H J, Mabkhot Y N, Ghabbour H A and Fun H-K 2014 RSC Adv. 4 4909

24. Barakat A, Al-Majid A M, Al-Najjar H J, Mabkhot Y N, Javaid S, Yousuf S and Choudhary M I 2014 Eur. J. Med. Chem. 84146

25. Barakat A, Al-Majid A M, Al-Najjar H J, Soliman S M, Mabkhot Y N, Rafi Shaik M H A and Fun H-K 2015 Spectrochim. Acta 147107

26. Sheldrick G M 1997 SHELXTL-PC (Version 5.1) (Siemens Analytical Instruments, Inc.: Madison, WI)

27. Sheldrick G M 2008 Acta Crystallogr. A 64112

28. Frisch M J et al. 2004 Gaussian03, Revision C.01 (Gaussian, Inc.: Wallingford, CT)

29. Keith T and Millam J, Gauss View Version 4.1, R. Dennington II, Semichem Inc.: Shawnee Mission, KS (2007)

30. Becke A D 1988 Phys. Rev. A 383098

31. Wang W and Mortier W J 1986 J. Am. Chem. Soc. 108 5708 
32. Glendening E D, Reed A E, Carpenter J E and Weinhold F 1998 NBO Version 3.1, CI, University of Wisconsin, Madison

33. Reed A E and Curtiss L A F 1988 Chem. Rev. 88 899

34. Frisch M J, Pople J A and Binkley J S 1984 J. Chem. Phys. 803265
35. Sidir I, Sidir Y G, Kumalar M and Tasal E $2010 \mathrm{~J}$. Mol. Struct. 964134

36. Murray J and Sen S K 1996 In Molecular Electrostatic Potentials, Concepts and Applications (Amsterdam: Elsevier)

37. Scrocco E and Tomasi J 1978 Adv. Quantum Chem. 11115 